\title{
Dermatological Disorders in Patients with Alcohol Dependence Syndrome: An Observational Clinical Study
}

\author{
Kumari Padma ${ }^{1}$, Supriya Hegde ${ }^{2}$, Aruna G Yadihal ${ }^{3}$, Siddharth Shetty ${ }^{4}$
}

\begin{abstract}
Background: Alcohol dependence syndrome is associated with many health problems especially skin change. There are various psychosocial implications in patients who have comorbid skin disorders. Nutritional deficiency due to malabsorption in alcohol dependence syndrome leads to nonhealing skin lesions. This study aimed to evaluate the frequency and spectrum of dermatological disorders in patients with alcohol dependence syndrome.

Materials and methods: Population for the study consisted of patients diagnosed of alcohol dependence syndrome admitted in deaddiction ward. Thirty consecutive patients with diagnosis of alcohol dependence syndrome formed the sample of the study. Thorough clinical examination was done for diagnosis of dermatological disorders with the help of a dermatologist.

Results: Majority of patients attending were in the age group of 31-40 years. Most of them were Christians, educated up to primary from a nuclear population. Higher significance was found in patients in joint families and with an income of less than 5,000 . The findings of this study revealed higher prevalence of tinea versicolor (13\%), seborrheic dermatitis (11\%), and scabies (2\%) in patients with alcohol dependence syndrome. Keywords: Alcohol dependence, Dermatological disorders, Skin lesions in alcoholism.

Indian Journal of Private Psychiatry (2019): 10.5005/jp-journals-10067-0032
\end{abstract}

\section{INTRODUCTION}

Excessive alcohol (ethanol) intake or alcohol abuse can result in many health problems and is implicated as a cause or aggravating factor for several skin conditions. Nutritional deficiency can develop when alcohol replaces normal food in the diet which results in malabsorption. ${ }^{1}$ With little calorie or protein intake, the skin becomes dry and loses elasticity. Skin infections occur more frequently in patients who drink alcohol excessively due to impairment of the immune system, nutritional deficiency, and increased trauma. Ninety-one percent have cutaneous, nail, hair, or oral cavity changes. ${ }^{2}$ Prevalence of oral changes in patients with alcohol use was most common (53.5\%). Tinea versicolor (14\%) and seborrheic dermatitis (11.5\%) are the most common cutaneous changes noted. ${ }^{2}$ Certain skin disorders have been demonstrated to be affected by alcohol misuse, ${ }^{3}$ in particular psoriasis and discoid eczema. ${ }^{4}$ Alcohol abuse is a risk factor for psoriasis both in men and in women. ${ }^{5}$ The pattern of involvement of psoriatic lesions in alcohol dependence syndrome differs from psoriasis vulgaris in character and distribution and tends to be more difficult to treat. ${ }^{4}$ Discoid eczema appears to be scientifically related to alcohol excess and is associated with deranged liver function tests. ${ }^{4}$ Among the diseases that can be exacerbated with alcohol, seborrhea capitis was seen in $11.5 \%$, diseases due to poor hygiene in $27.5 \%$, and pityriasis versicolor, $14 \% .{ }^{5} \mathrm{~A}$ study conducted by Rosset and Oki found the prevalence of skin diseases to be $43 \%$ in male and $33 \%$ in female alcoholics; $44 \%$ had one or more skin conditions. ${ }^{5}$ Alcohol has a profound influence on the immune function and induces changes in cutaneous vasculature. The prevalence and severity of some skin diseases are increased in patients prone to excessive alcohol intake, more than $500 \mathrm{~mL}$ per day for more than 10 years. ${ }^{5}$

Alcohol can give rise to allergic or allergy-like symptoms. Along with urticaria, patients may develop low blood pressure, diarrhea, shortness of breath, and low heart rate. Along with increasing
${ }^{1}$ Department of Psychiatry, BKL Walawalkar Rural Medical College and Research Centre, Sawarde, Ratnagiri, Maharashtra, India

${ }^{2-4}$ Department of Psychiatry, Father Muller Medical College, Mangaluru, Karnataka, India

Corresponding Author: Kumari Padma, Department of Psychiatry, BKL Walawalkar Rural Medical College and Research Centre, Sawarde, Ratnagiri, Maharashtra, India, Phone: +91 9008940879, e-mail: skpadma444@gmail.com

How to cite this article: Padma K, Hegde S, Yadihal AG, et al. Dermatological Disorders in Patients with Alcohol Dependence Syndrome: An Observational Clinical Study. Ind J Priv Psychiatry 2019;13(1):4-6.

Source of support: Nil

Conflict of interest: None

the risk of liver, pancreatic, and breast cancer, alcohol increases the risk of skin cancer including squamous cell carcinoma, basal cell carcinoma, and melanoma. The probable mechanism is it suppresses the immune system and impairs adequate nutrition, reducing the body's natural defense against skin cancer. Secondly its main metabolite, acetaldehyde, is a carcinogen (cancer-causing chemical). Acetaldehyde also produces reactive free radicals and damages DNA. ${ }^{6}$

Long-term alcohol abuse is often associated with dermatologic stigmata of liver disease. Alcohol abuse is one of the leading causes of cirrhosis and should be considered in patients with cutaneous findings of liver disease. ${ }^{7}$ There are multiple cutaneous findings in alcoholic liver disease. Superficial erythematous macule with radiating arterioles called spider angiomas are common. Alcoholinduced vasodilation or elevated estrogen levels have been implicated as cause of these lesions. ${ }^{8}$ Caput medusae occurring in alcoholics may indicate alcoholic liver disease or portal hypertension. ${ }^{9}$ 
Increased skin-surface involvement and diminished treatment responsiveness in alcohol abusers may be evidence that alcohol exacerbates psoriasis. ${ }^{10-12}$ Other dermatologic disorders associated with alcohol abuse include rosacea, nummular eczema, ${ }^{10}$ and seborrheic dermatitis. ${ }^{13}$

Though a number of studies have been reported from western world, there is paucity of recent Indian literature on prevalence of dermatological disorders in alcohol dependence syndrome.

\section{Materials and Methods}

This study was conducted in the Department of Psychiatry in Father Muller Medical College during the period from October 2015 to December 2015. It included 30 patients admitted in deaddiction ward with diagnosis of alcohol dependence syndrome. It is an observational clinical study. This study was approved by the Institutional Ethics Committee. A structured proforma was created and a written informed consent was taken from the patients. All patients who consented for the study and those who satisfied the inclusion and exclusion criteria were included in the study. Inclusion criteria for the study were the patients with definite diagnosis of alcohol dependence syndrome in the age group of 20-65 years and individuals who were consenting for study. Patients with primary dermatological disorders before the onset of alcohol dependence syndrome and patients on drugs known to cause skin disorders were excluded from the study. All patients were subjected to thorough clinical examination for diagnosis of dermatological disorders with the help of a dermatologist. The collected data were analyzed by frequency, percentage, Chi-square test, and Fischer's exact test.

\section{Results}

\section{Sociodemographic Data}

The demographic profile of the patients admitted in deaddiction ward revealed majority were in the age group between 31 years and 40 years $(n=10 / 30)$. Majority of the patients were male. Majority of subjects attending were Christians of the backward caste $(n=$ $20 / 30, n=17 / 30$ ). The educational status was up to primary school $(n=11 / 30)$. They hailed from rural population $(n=23 / 30)$. Majority of members in the sample were married $(n=23 / 30)$. Most of the subjects were unskilled laborers $(n=14 / 30)$ (Table 1$)$.

Table 1: Sociodemographic data

\begin{tabular}{lcll}
\hline Variable & Subjects & p value & Significance \\
\hline Age & & & \\
$21-30$ & 8 & - & NS \\
$31-40$ & 10 & & \\
$41-50$ & 5 & & \\
$51-60$ & 7 & & NS \\
Gender & & & \\
Male & 30 & - & NS \\
Female & 0 & & \\
Religion & & & \\
Hindu & 20 & 0.921 & \\
Muslim & 4 & & \\
Christian & 2 & & \\
Others & 0 & & \\
\hline
\end{tabular}

\begin{tabular}{|c|c|c|c|}
\hline Variable & Subjects & pvalue & Significance \\
\hline \multicolumn{4}{|l|}{ Caste } \\
\hline Dominant caste & 12 & 0.123 & NS \\
\hline Backward class & 17 & & \\
\hline Scheduled caste & 1 & & \\
\hline \multicolumn{4}{|l|}{ Educational status } \\
\hline Illiterate & 4 & 0.121 & NS \\
\hline Primary & 11 & & \\
\hline Middle school & 4 & & \\
\hline High school & 7 & & \\
\hline Plus 2/predegree & 3 & & \\
\hline Degree & 1 & & \\
\hline Postgraduate & 0 & & \\
\hline Professional degree & 0 & & \\
\hline \multicolumn{4}{|l|}{ Marital status } \\
\hline Single & 4 & 0.623 & NS \\
\hline Married & 23 & & \\
\hline Living together & 0 & & \\
\hline Separated & 0 & & \\
\hline Divorced & 0 & & \\
\hline Widow/Widower & 0 & & \\
\hline Remarried & 0 & & \\
\hline \multicolumn{4}{|l|}{ Occupation } \\
\hline Unskilled labor & 14 & 0.420 & NS \\
\hline Skilled labor & 13 & & \\
\hline Government employee & 1 & & \\
\hline Private employee & 1 & & \\
\hline Self-employment & 1 & & \\
\hline Business & 0 & & \\
\hline Professional & 0 & & \\
\hline Others & 0 & & \\
\hline \multicolumn{4}{|l|}{ Residence } \\
\hline Urban & 7 & 0.377 & NS \\
\hline Rural & 23 & & \\
\hline \multicolumn{4}{|l|}{ Type of family } \\
\hline Nuclear & 10 & 0.001 & $\mathrm{HS}$ \\
\hline Joint & 16 & & \\
\hline Extended & 4 & & \\
\hline Others & 0 & & \\
\hline \multicolumn{4}{|l|}{ Monthly income } \\
\hline$<5,000$ & 12 & 0.010 & $S$ \\
\hline $5,000-10,000$ & 13 & & \\
\hline $11,000-20,000$ & 5 & & \\
\hline $21,000-30,000$ & 0 & & \\
\hline$>30,000$ & 0 & & \\
\hline
\end{tabular}

\section{Clinical Data}

The results of the present study revealed that there was increased frequency of dermatological disorder (Fig. 1) in patients with alcohol dependence syndrome (26\%). The most prevalent were tinea versicolor (13\%), seborrheic dermatitis (11\%), and scabies (2\%). There was high statistical significance found in patients residing in joint families. Significance was also reported in patients with an income of less than 5,000 (Fig. 2). 


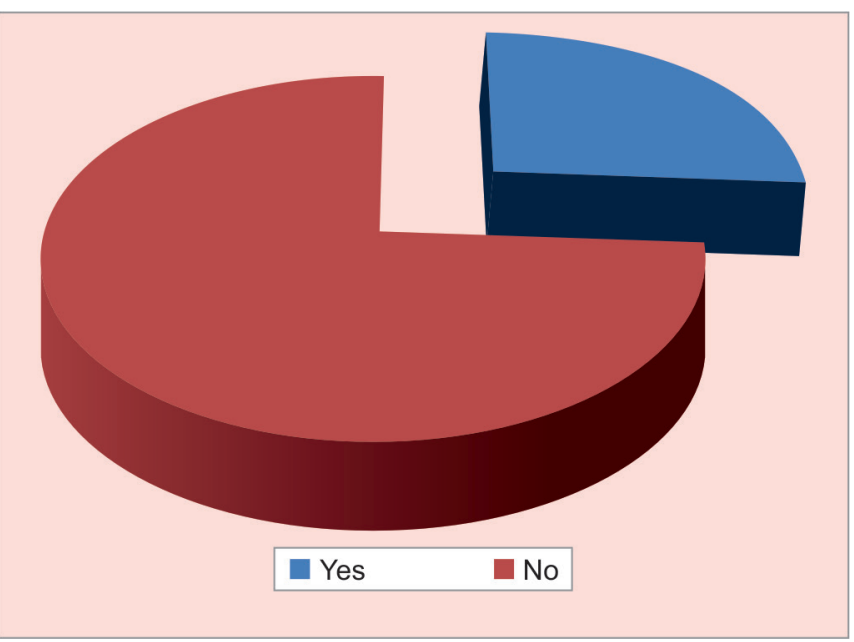

Fig. 1: Presence of dermatological disorders

\section{Discussion}

Cutaneous abnormality have been associated with alcohol use. These are either caused indirectly through impaired functioning of other organ systems or directly from toxic effects of alcohol on skin. The sociodemographic profile of the patients in our study revealed male preponderance. Most of the patients in current study were between 31 years and 40 years of age. The finding of the current study was consistent with the study done by Rosset and Oki. ${ }^{5}$

Demographic data on religion and caste cannot be commented upon and compared to studies done elsewhere as the results are confounded based on study conducted in that particular region. There was statistical significant correlation between the monthly income and frequency of dermatological disorders. This study revealed a higher frequency of dermatological disorders in patients residing in joint families. This can be attributed to the multiple factors, including alcohol-associated nutritional deficiencies. No similar studies pointing out a significant correlation between socioeconomic status/demographic data and dermatological disorders in patients with alcohol dependence syndrome.

The results of the present study revealed that there was increased frequency of dermatological disorder in patients with alcohol dependence syndrome (26\%). The findings of this study revealed higher prevalence of tinea versicolor (13\%), seborrheic dermatitis (11\%), and scabies (2\%) in patients with alcohol dependence syndrome. The finding of the above was consistent with those of previous studies. ${ }^{1,2}$

Our study also emphasized the need for a multimodal approach in treating patients with alcohol dependence syndrome. An effective teamwork often interdisciplinary is necessary for the effective management of psychiatric and psychological problems in these patients.

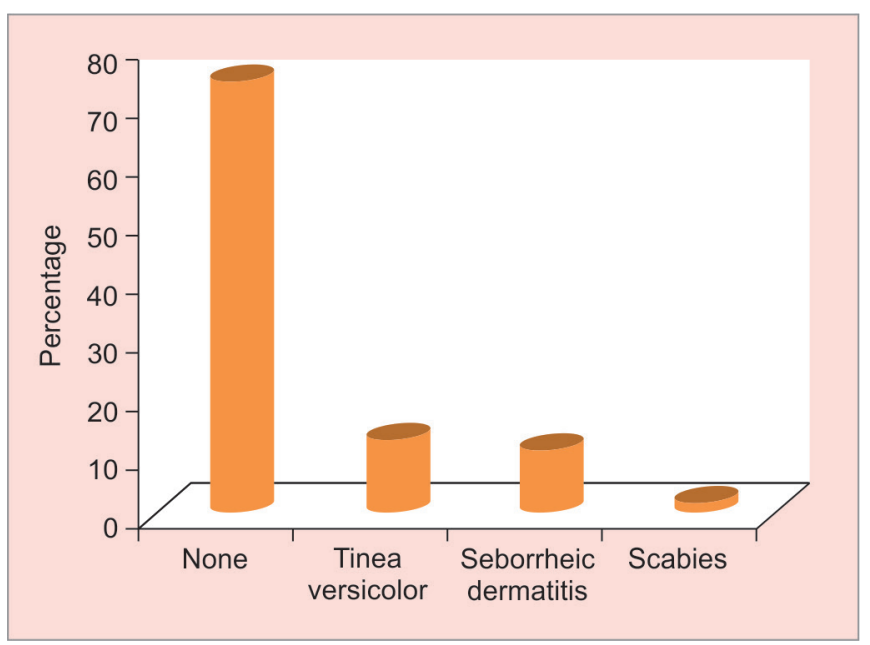

Fig. 2: Type of dermatological disorders

\section{Conclusion}

Psychodermatology has evolved as a new and emerging subspecialty of both psychiatry and dermatology. Psychiatric factors are instrumental in the etiology and course of skin conditions.

\section{References}

1. Kostoviae K, Lipozeneiae J. Skin diseases in Alcoholics. Acta Dermatovenerol Croat 2004;12:181-190.

2. Rao GS. Cutaneous manifestations in chronic alcoholics. IJDVL 2004; 79-88.

3. Shellow WVR. The skin in alcoholism. Int J Dermatol 1983;22: 506-510. DOI: 10.1111/j.1365-4362.1983.tb02188.x.

4. Higgins EM, du Vivier AWP. Cutaneous disease and alcohol misuse. $\mathrm{Br}$ Med Bull 1994;50:85-97. DOI: 10.1093/oxfordjournals.bmb.a072887.

5. Rosset M, Oki G. Skin diseases in alcoholics. Q J Stud Alcohol 1971;32:1017-1024.

6. Millard LG, Gotterill JA. Psychocutaneous disorders. Rook's Textbook of Dermatology, 7th ed., vol. IV, ch. 61, Malden, MA: Blackwell Publishing Company; 2004.

7. Heidelbaugh JJ, Bruderly M. Cirrhosis and chronic liver failure: part I. Diagnosis and evaluation. Am Fam Physician 2006;74:756-762.

8. Smith KE, Fenske NA. Cutaneous manifestations of alcohol abuse. J Am Acad Dermatol 2000;43:1-16. DOI: 10.1067/mjd.2000.104512.

9. Liu SW, Lien MH, Fenske NA. The effects of alcohol and drug abuse on the skin. Clin Dermatol 2010;28:391-399. DOI: 10.1016/ j.clindermatol.2010.03.024.

10. Higgins EM, du Vivier AW. Alcohol and the skin. Alcohol 1992;27: 595-602.

11. Ghosn SH, Kibbi AG. Cutaneous manifestations of liver diseases. Clin Dermatol 2008;26:274-282. DOI: 10.1016/j.clindermatol.2008.02.001.

12. Gupta MA, Schork NJ, Gupta AK, et al. Alcohol intake and treatment responsiveness of psoriasis: a prospective study. J Am Acad Dermatol 1993;28:730-732. DOI: 10.1016/0190-9622(93)70101-X.

13. Rosset M, Oki G. Skin diseases in alcoholics. Q J Stud Alcohol 1971;32:1017-1024. 